\title{
Heads or tails? Stressor-specific expression of corticotropin-releasing factor and urotensin I in the preoptic area and caudal neurosecretory system of rainbow trout
}

\author{
Nicholas J Bernier, Sarah L Alderman and Erin N Bristow \\ Department of Integrative Biology, University of Guelph, 488 Gordon Street, Guelph, Ontario, Canada N1G 2W1 \\ (Correspondence should be addressed to N J Bernier; Email: nbernier@uoguelph.ca)
}

\begin{abstract}
Corticotropin-releasing factor (CRF)- and urotensin I (UI)-expressing cells of the preoptic area (POA) and caudal neurosecretory system (CNSS) are considered key contributors to the regulation of the stress response in fish; however, the expression pattern of these neurons to environmental and social challenges have not been compared in a single study. Therefore, we characterized in rainbow trout (Oncorhynchus mykiss) the central distribution of CRF and UI expression and quantified the POA and CNSS mRNA levels of both transcripts in response to hyperammonemia, hypoxia, isolation, or subordination. The tissue distribution demonstrated that the POA and the CNSS are dominant sites of CRF and UI expression. Comparison of the plasma cortisol levels in response to the diverse treatments showed that subordination was the most severe stressor followed by hyperammonemia,
\end{abstract}

isolation, and hypoxia. In the POA, with the exception of subordination that had no effect on UI expression, all stressors resulted in increase in CRF and UI mRNA levels. In the CNSS, while hyperammonemia was associated with increase in CRF and UI mRNA levels, and hypoxia induced an increase in CRF expression, isolation caused a decrease in the expression of both transcripts, and subordination had no effect. Independent of the stressor, we found strong positive correlations between CRF and UI expression in the POA and the CNSS, and no correlation in the expression of either gene between regions. Overall, the results demonstrate that the contribution of POA and CNSS CRF and UI neurons to the stress response in rainbow trout is stressor-, time-, and region-specific.

Journal of Endocrinology (2008) 196, 637-648

\section{Introduction}

The corticotropin-releasing factor (CRF) system is a key player in the coordination and regulation of the vertebrate stress response. In teleosts, as in amphibians and mammals, the CRF system is composed of four paralogous lineages of CRF-related peptides, namely CRF, urotensin I (UI), and homologs to urocortin 2 and 3 (Boorse et al. 2005). Similarly, the CRFrelated peptides in teleosts as in other vertebrates bind to two main receptor types (Chang \& Hsu 2004) and their actions maybe modulated by a binding protein (Huising et al. 2004). Although the CRF is broadly expressed in the central nervous system (CNS) of vertebrates (Swanson \& Sawchenko 1983, Alderman \& Bernier 2007), the principal site of hypophysiotropic CRF neurons in the teleost brain, the preoptic area (POA), is homologous to the hypophysiotropic CRF neurons of the paraventricular nucleus (PVN) in mammals. While the teleost CRF system has several features in common with other animals, it is also characterized by unique attributes. Teleosts differ from other vertebrates in having an additional major site of CRF-related peptide synthesis, the caudal neurosecretory system (CNSS). Located in the terminal segments of the spinal cord, the CNSS has high expression levels of CRF and UI

(Lu et al. 2004, Craig et al. 2005) and a neurohemal organ from which these peptides can be released to the circulation (Winter et al. 2000). Despite its uniqueness among vertebrates and distinct advantages for studying CRF and UI neurosecretion, many fundamental questions regarding the physiological roles of the CNSS remain unresolved (McCrohan \& Bernier 2007).

The CRF and UI in teleosts are implicated in the regulation of the neuroendocrine, autonomic, and behavioral responses to stressors (Lovejoy \& Balment 1999, Flik et al. 2006). While it is not known whether UI-producing neurons directly innervate the pituitary like the CRF-producing neurons of the POA (Matz \& Hofeldt 1999, Zupanc et al. 1999), both UI and CRF are potent in vitro stimulants of adrenocorticotropic hormone (ACTH; Fryer et al. 1983), melanocyte-stimulating hormone (Tran et al. 1990), and thyrotrophin (Larsen et al. 1998) secretion from fish pituitary cells. Therefore, the CRF- and UI-producing cells of the fish brain may both contribute to the pituitary control of interrenal cortisol secretion, melanophore pigment dispersal, and thyroid hormone production. In some fish species, but not in others (Pepels et al. 2004), the CRF-related peptides can also directly stimulate cortisol secretion from the interrenals (Arnold-Reed \& Balment 1994, Kelsall \& Balment 1998). The CNSS 
CRF-related peptides may therefore provide a hypothalamicpituitary-interrenal (HPI) axis-independent means of regulating cortisol secretion. Beyond their role in the control of the endocrine stress response, the CRF-related peptides of the CNS in teleosts appear to be involved in regulation of cardiovascular control (Le Mével et al. 2006), locomotor activity (Lowry \& Moore 2006), osmoregulation (Craig et al. 2005, Lu et al. 2007), and food intake (Bernier 2006). Overall, while diverse physiological actions have been attributed to CRF and UI in fish, our understanding of the relative involvement of either peptide toward specific functions remains largely elusive.

Several studies have assessed the responsiveness of POA CRF neurons to stressors in fish, yet few have investigated the impact of stressors on UI expression in this region or on the CRF-related peptides in the CNSS. As seen in the PVN of mammals (for review see Bakshi \& Kalin 2000), exposure to a variety of stressors in teleosts can elicit an increase in the expression of CRF in the POA (Doyon et al. 2003, 2005, Huising et al. 2004, Bernier \& Craig 2005, Craig et al. 2005). In the CNSS, while an increase in osmolality is associated with increase in both CRF and UI gene expression (Craig et al. 2005, Lu et al. 2007), physical restraint transiently activates CRF but not UI neurons ( $\mathrm{Lu}$ et al. 2004). Overall, results from studies where the impact of a stressor on the expression of the CRF-related peptides was assessed in more than one region of the CNS suggest that the regulation of CRF and UI gene expression in teleosts maybe regionally specific (Lu et al. 2004, Craig et al. 2005).

To build on the above observations, the present study was undertaken to gain a better understanding of the potential roles played by CRF and UI in the stress response of fish and of the general responsiveness of the POA and the CNSS to diverse stressors. Toward these goals we first characterized the mRNA levels of CRF and UI in ten regions of the rainbow trout CNS to assess the relative importance of the POA and the CNSS as sites of CRF and UI expression in this species. We then investigated the impact of two environmental stressors, elevated ammonia levels and hypoxia, and two social stressors, isolation and subordination on the mRNA levels of CRF and UI in the POA and the CNSS of rainbow trout.

\section{Materials and Methods}

\section{Animals}

Mixed sex rainbow trout (Oncorhynchus mykiss) were obtained from Rainbow Springs Trout Farm (Thamesford, ON, Canada) and transported to the Hagen Aqualab at the University of Guelph (Guelph, ON, Canada). Fish were acclimated for at least 4 weeks in 6501 fiberglass tanks continuously supplied with flow-through well water $(\mathrm{pH} 7 \cdot 9$; water hardness $411 \mathrm{mg} / \mathrm{l}$ as $\mathrm{CaCO}_{3} ; \mathrm{Ca}^{2+}, 10.5 \mathrm{mmol} / 1 ; \mathrm{Cl}^{-}$, $1.5 \mathrm{mmol} / \mathrm{l} ; \mathrm{Mg}^{2+}, 3.0 \mathrm{mmol} / \mathrm{l} ; \mathrm{K}^{+}, 0.06 \mathrm{mmol} / \mathrm{l} ; \mathrm{Na}^{+}$, $1.1 \mathrm{mmol} / \mathrm{l})$, maintained at $13{ }^{\circ} \mathrm{C}$, and exposed to a $12 \mathrm{~h}$ light:12 h darkness photoperiod regime. Fish were fed daily with commercial trout pellets (4PT Classic Sinking, Martin Mills, Elmira, Canada). All procedures were approved by the local Animal Care Committee and conform to the principles of the Canadian Council for Animal Care.

\section{CNS distribution of CRF and UI gene expression}

Fish of either sex weighing $\sim 200 \mathrm{~g}(n=7)$ were terminally anesthetized in $2 \mathrm{ml} / 1$ 2-phenoxyethanol (Sigma-Aldrich) and placed on ice. The CNS was regionally dissected into ten parts: eight brain regions, the pituitary, and the CNSS (Fig. 1A). All brain tissues and the pituitaries were snap frozen in liquid nitrogen and stored at $-80{ }^{\circ} \mathrm{C}$ until total RNA extraction. The region of the caudal spinal cord removed consisted of the six most caudal vertebrae and the urostyle after Craig et al. (2005). The CNSS was placed in a solution of $4 \%$ paraformaldehyde (PFA) in PBS ( $\mathrm{pH} 7 \cdot 4$ ) for $24 \mathrm{~h}$ at $4{ }^{\circ} \mathrm{C}$.

\section{Experimental design}

Experiment 1: ammonia stress Four groups of 12 fish $(280.5 \pm 6.8 \mathrm{~g})$ were acclimated for a 3-week period to individual 1251 fiberglass tanks. After this acclimation period, two groups were exposed to chronic flow-through ammonia conditions, one for $24 \mathrm{~h}$ and the other for $96 \mathrm{~h}$, and two groups were maintained in normal water and served as time controls. Using a prepared stock solution of ammonium chloride $\left(\mathrm{NH}_{4} \mathrm{Cl}\right)$, ammonia levels in the tanks were increased instantaneously to $600 \mu \mathrm{mol} / 1$ and maintained at this level using a peristaltic pump (Minipuls 3, Gilson, Villiers Le Bel, France). Water samples were collected prior to the exposure, immediately after the start of the experiment, and every $6 \mathrm{~h}$ thereafter to monitor the $\mathrm{pH}$ and water ammonia levels. All fish were last fed $24 \mathrm{~h}$ prior to the exposure and fasted throughout the experiment.

Experiment 2: hypoxia stress Four groups of 12 fish $(283 \cdot 6 \pm 6 \cdot 1 \mathrm{~g})$ were acclimated for a 3-week period to individual 1251 fiberglass tanks. After this acclimation period, two groups were chronically exposed to a $\mathrm{PO}_{2}$ of $35 \%$ (percentage of dissolved $\mathrm{O}_{2}$ saturation; $3.7 \mathrm{mg} / \mathrm{l}$ ), one for $24 \mathrm{~h}$ and the other for $96 \mathrm{~h}$, and two groups were maintained at $\mathrm{PO}_{2}$ of $100 \%(10.6 \mathrm{mg} / \mathrm{l})$ and served as time controls. The desired hypoxic conditions were achieved by bubbling $\mathrm{N}_{2}$ gas into a stripping column that supplied the holding tanks. Levels of dissolved $\mathrm{O}_{2}$ were continuously monitored using $\mathrm{O}_{2}$ sensors (Point-Four Systems, Port Moody, BC, Canada) and a data acquisition system (Argus Control Systems Ltd, White Rock, BC, Canada). The desired hypoxic level was gradually achieved over a $2-\mathrm{h}$ period by regulating the flow of water and $\mathrm{N}_{2}$ gas through the stripping column. All fish were last fed $24 \mathrm{~h}$ prior to the exposure and fasted throughout the experiment.

Experiment 3: isolation stress Five groups of 11 fish $(193 \cdot 6 \pm 5 \cdot 0 \mathrm{~g})$ were acclimated for a 3-week period to 1251 
A
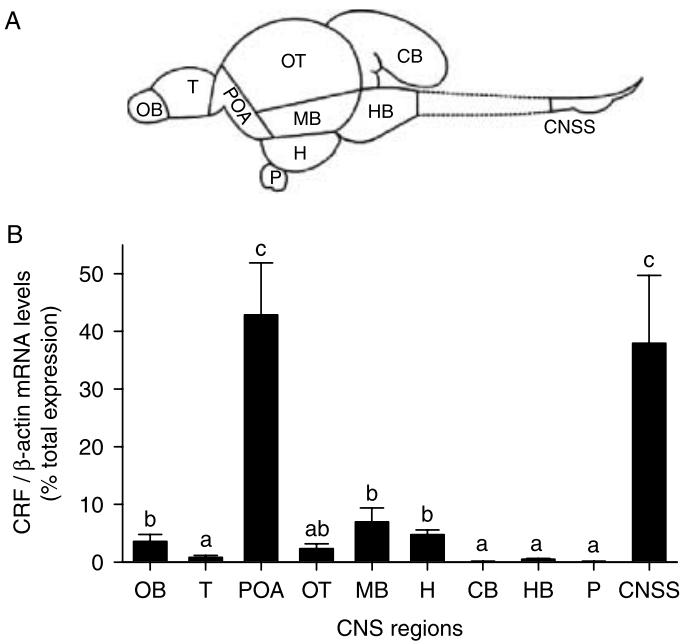

C

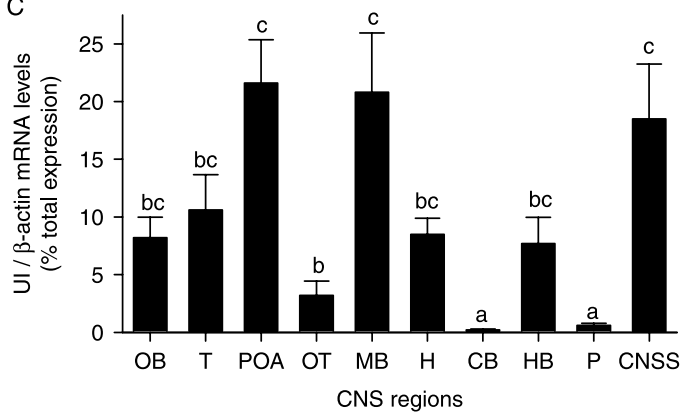

D

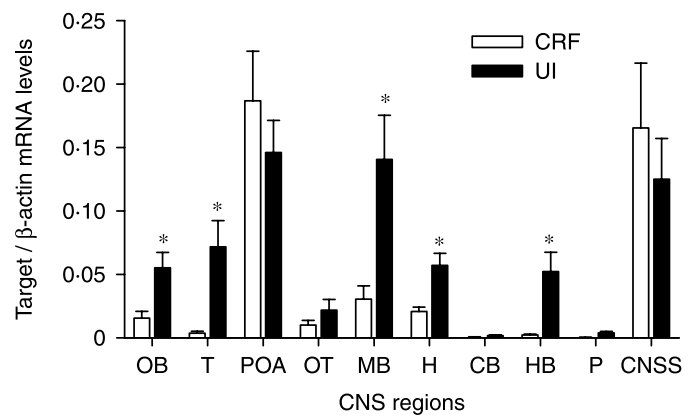

Figure 1 Distribution of corticotropin-releasing factor (CRF) and urotensin I (UI) mRNA in the central nervous system (CNS) of rainbow trout. (A) Schematic of the trout CNS showing the ten regions assayed by real-time RT-PCR for CRF and UI mRNA levels: the caudal neurosecretory system (CNSS), cerebellum (CB), hypothalamus $(\mathrm{H})$, hindbrain $(\mathrm{HB})$, midbrain $(\mathrm{MB})$, olfactory bulbs $(\mathrm{OB})$, optic tectum $(\mathrm{OT})$, pituitary $(\mathrm{P})$, preoptic area $(\mathrm{POA})$, and telencephalon (T). (B) The ratio of CRF or (C) UI to $\beta$-actin mRNA levels as a percentage of total expression. (D) Direct comparison of the ratio of CRF or UI to $\beta$-actin mRNA levels. For a given gene, bars that do not share a common letter are significantly different from each other as determined by one-way ANOVA and by pairwise Student-Newman-Keuls test. *Indicates a significant difference between target genes for a given brain region as determined by Student's $t$-test $(n=7 ; P<0 \cdot 05)$. fiberglass tanks. After this acclimation period, the fish from two groups were anesthetized for $90 \mathrm{~s}$ in a buffered $\left(\mathrm{NaHCO}_{3}, 0 \cdot 2 \mathrm{~g} / \mathrm{l}\right)$ solution of tricaine methanesulfonate $(0 \cdot 1 \mathrm{~g} / 1$; MS-222; Syndel, Vancouver, BC, Canada) and then individually confined to covered 91 flow-through tanks and kept isolated for either 24 or $96 \mathrm{~h}$. Two control groups were anesthetized as above and returned to their respective 1251 tank for either 24 or $96 \mathrm{~h}$ (handled controls). One control group was left undisturbed and terminally anesthetized $24 \mathrm{~h}$ after the beginning of the experiment (unhandled control). All fish were fed for the last time $24 \mathrm{~h}$ prior to the beginning of the experiment and fasted throughout.

Experiment 4: subordination stress On the basis of their body weight 16 pairs of rainbow trout were size matched (average weight: $91 \cdot 2 \pm 2 \cdot 3 \mathrm{~g}$; average weight difference within a pair: $2 \cdot 8 \pm 0 \cdot 4 \mathrm{~g}$ ). To visually identify individuals within a pair, each fish was tagged with a uniquely colored $6 \mathrm{~mm}$ plastic disc loosely sutured to the skin anterior to the dorsal fin. Fish from each pair were then placed in 361 flow-through aquaria and separated by an opaque divider for a 72-h acclimation period. Prior to weighing, tagging, and transfer, fish were lightly anesthetized in a buffered $\left(\mathrm{NaHCO}_{3}, 0 \cdot 2 \mathrm{~g} / \mathrm{l}\right)$ solution of MS$222(0 \cdot 1 \mathrm{~g} / \mathrm{l})$. After acclimation, the divider was removed and the fish were allowed to interact for 8 or $24 \mathrm{~h}$. During this time, social ranks were determined through indirect behavioral observations using mirrors placed at an angle above the tanks. Dominance was measured by assigning points for aggressive behavior, position in the tank, and food acquisition as per Doyon et al. (2003) such that the fish within a pair with the higher score was identified as dominant and the fish with the lower score as subordinate. Fish were fed daily throughout the experiment.

\section{Experimental procedures}

Terminal sampling At the end of Experiments 1-4, fish were quickly netted from their tank or aquarium, terminally anesthetized with an overdose of 2-phenoxyethanol as above and a blood sample was collected by caudal puncture using a $\mathrm{K}_{2}$ EDTA (0.5 M, pH 8.0)-treated syringe. Blood samples were immediately centrifuged at $15000 \mathrm{~g}$ for $5 \mathrm{~min}$ and the separated plasma frozen at $-80{ }^{\circ} \mathrm{C}$ for subsequent measurement of plasma cortisol (Experiments 1-4) and plasma ammonia (Experiment 1) concentrations. Additionally, to quantify CRF and UI mRNA levels, the brain was removed, regionally dissected to isolate the POA, and immediately frozen in liquid nitrogen. The CNSS was also excised and fixed in PFA overnight to quantify CRF and UI mRNA levels.

Ammonia determinations Water ammonia was measured using the method described by Verdouw et al. (1978). Plasma samples were assayed for ammonia using the glutamate dehydrogenase enzymatic assay of Kun \& Kearney (1971). Briefly, plasma samples were deproteinized with two volumes of trichloroacetic acid $(10 \% \mathrm{w} / \mathrm{v})$ and centrifuged at $15000 \boldsymbol{g}$ for $10 \mathrm{~min}$ at $4{ }^{\circ} \mathrm{C}$. The supernatant was neutralized with potassium 
hydrogen carbonate $\left(\mathrm{KHCO}_{3} ; 2 \mathrm{M}\right)$ and centrifuged at $7500 \mathrm{~g}$ for $30 \mathrm{~s}$ at $4{ }^{\circ} \mathrm{C}$. The enzymatic assay was adapted for 96 -well microtiter plates. All samples were run in triplicate at $24^{\circ} \mathrm{C}$ with shaking in a SpectraMax 190 plate reader (Molecular Devices, Menlo Park, CA, USA) and changes in absorbance at $340 \mathrm{~nm}$ were recorded until all reactions had gone to completion. Ammonia standards were prepared fresh in distilled water, and the plasma ammonia concentrations were determined from a linear regression of the standards using SOFTmax software 4.6 (Molecular Devices). All ammonia concentrations reported refer to total ammonia-N.

Cortisol determination Plasma cortisol was determined in triplicate using a RIA. Briefly, $200 \mu \mathrm{l}$ appropriate standard or plasma sample diluted with assay buffer $\left(21 \cdot 4 \mathrm{mM} \mathrm{Na}_{2} \mathrm{HPO}_{4} \cdot 7\right.$ $\mathrm{H}_{2} \mathrm{O} ; 9 \cdot 3 \mathrm{mM} \mathrm{NaH} \mathrm{PO}_{4} \cdot \mathrm{H}_{2} \mathrm{O} ; \mathrm{pH} 7 \cdot 6 ; 0 \cdot 1 \%$ gelatin; $0 \cdot 01 \%$ thimerosal) was incubated overnight at $4{ }^{\circ} \mathrm{C}$ with $200 \mu \mathrm{l}$ $\left[{ }^{3} \mathrm{H}\right]$ cortisol $(6000$ c.p.m.; $69.0 \mathrm{Ci} / \mathrm{mmol}$; Amersham Biosciences) and $200 \mu \mathrm{l}$ diluted rabbit anti-cortisol antibody (cat \# F3-314, Esoterix Endocrinology, Calabasas Hills, CA, USA). These mixtures were then cooled on ice for $10 \mathrm{~min}$ prior to the addition of $200 \mu \mathrm{l}$ Dextran-coated charcoal suspension containing $0.5 \%$ activated charcoal and $0.05 \%$ Dextran (Sigma) in assay buffer. After a further 10-min incubation on ice, the samples were centrifuged at $1830 \mathrm{~g}$ for $10 \mathrm{~min}$ at $4{ }^{\circ} \mathrm{C}$. The resulting supernatant was combined with $5 \mathrm{ml}$ scintillation cocktail $(667 \mathrm{ml}$ toluene, $333 \mathrm{ml}$ Triton X-100, 4 g 2,5diphenyloxazole, and $0 \cdot 2 \mathrm{~g}$ 1,4-bis[5-Phenyl-2-oxazolyl]benzene; 2,2'-p-Phenylene-bis[5-phenyloxazole]; Sigma) and counted in a multipurpose scintillation counter (LS 6500, Beckman, Fullerton, CA, USA). The antibody concentration used was adjusted so that $40-50 \%$ of the radiolabeled cortisol was bound in the absence of competitor. Plasma cortisol concentrations were determined using a three-parameter sigmoidal curve regression equation (SigmaPlot 10.0, SPSS, Chicago, IL, USA) obtained from the standard curve. A serial dilution of rainbow trout plasma gave a displacement curve that was parallel to the standard curve and the lower detection limit of the assay was $16 \mathrm{pg} / \mathrm{ml}$. Using a pooled plasma sample stock, the intraand interassay variations were $3 \cdot 2 \%(n=6)$ and $5 \cdot 3 \%(n=6)$ respectively. Cortisol was measured in unextracted plasma that was either diluted ten times in assay buffer (control fish) or further diluted (treated fish) in order to fall within the $20-80 \%$ range of the standard curve.

Total RNA extraction Total RNA from the brain regions was extracted using TRIzol Reagent (Invitrogen) based on the acid guanidinium thiocyanate-phenol-chloroform extraction method. Total RNA from the CNSS was extracted according to Craig et al. (2005). Briefly, the urophysis and attached portion of the spinal cord were removed from the PFA-fixed vertebral column, dehydrated in a series of ethanol washes and incubated overnight at $4{ }^{\circ} \mathrm{C}$ in $100 \%$ ethanol. The ethanol was replaced with $1 \mathrm{ml}$ digestion buffer $(200 \mathrm{mM}$ Tris- $\mathrm{HCl}$, $200 \mathrm{mM} \mathrm{NaCl}, 1.5 \mathrm{mM} \mathrm{MgCl}$, 2\% SDS, pH 7.5) containing $500 \mu \mathrm{g}$ proteinase $\mathrm{K}$ (Invitrogen), and the mixture was incubated at $37^{\circ} \mathrm{C}$ until complete tissue lysis (90-120 min). Tissue lysate was incubated in $0.5 \mathrm{ml}$ phenol/chloroform per isoamyl alcohol (25:24:1; Sigma) at room temperature, centrifuged, and the upper phase precipitated overnight at $-20^{\circ} \mathrm{C}$ in isopropranol. Total RNA concentrations from all tissues were determined by u.v. spectrophotometry at $260 \mathrm{~nm}$ and samples were stored at $-80^{\circ} \mathrm{C}$ until used.

Quantification of mRNA by real-time RT-PCR One microgram of total RNA was treated with DNase I (DNase I amplification grade, Invitrogen) and reverse transcribed to cDNA using SuperScript II RNase $\mathrm{H}^{-}$reverse transcriptase (Invitrogen) according to the manufacturer's protocols. The cDNA product was amplified using the ABI Prism 7000 Sequence Detection System (Applied Biosystems, Foster City, CA, USA). Each reaction contained $10 \mu \mathrm{l}$ SYBR Green PCR Master Mix (Applied Biosystems), $5 \mu \mathrm{l}$ cDNA template, and $2 \cdot 5 \mu \mathrm{l}$ each of forward and reverse primers $(0 \cdot 4 \mu \mathrm{M})$. Default cycling conditions were used: $10 \mathrm{~min}$ at $95{ }^{\circ} \mathrm{C}$ followed by 40 cycles of $15 \mathrm{~s}$ at $95^{\circ} \mathrm{C}$ and $1 \mathrm{~min}$ at $60^{\circ} \mathrm{C}$. This protocol was followed by a melting curve analysis to verify the specificity of the PCR products. To account for differences in amplification efficiency, a standard curve was constructed for each target using serial dilutions of cDNA. Input values were obtained by fitting the average threshold cycle value to the antilog of the standard curve. To correct for minor variations in template input and transcriptional efficiency, each sample was normalized to the expression level of the housekeeping gene $\beta$-actin (distribution survey) or elongation factor- $1 \alpha$ (EF1 $\alpha$ ); stress experiments. In the distribution survey, to account for regional differences in $\beta$-actin expression levels, all input values were corrected to the mean input of the hypothalamus (arbitrarily chosen). The EF1 $\alpha$ was used for normalization in the stress experiments as the level of $\beta$-actin mRNA can be affected by exposure to cortisol (Alderman, unpublished observation). All samples were assayed in triplicate and only one target was assayed per well. Finally, non-reverse transcribed RNA and water controls were run to ensure that no genomic DNA was being amplified and the reagents were not contaminated. Primers for rainbow trout UI (GenBank accession no. AJ005264; forward: 5'-AGG AGA CAA AAT ACC GGG CA-3'; reverse: $5^{\prime}$-CTT CAT AGT GCT GGA CAG ACG G-3'), CRF (GenBank accession no. AF296672; forward: 5'-ACA ACG ACT CAA CTG AAG ATC TCG-3'; reverse: $5^{\prime}$-AGG AAA TTG AGC TTC ATG TCA GG-3'), $\beta$-actin (GenBank accession no. AJ438158; forward: $5^{\prime}$-GCC CCC CTC AAC CCC- $3^{\prime}$; reverse: $5^{\prime}$-GAA GGT CTC AAA CAT AAT CTG GGT C-3'), and EF1 $\alpha$ (GenBank accession no. AF498320; forward: 5'-GGG CAA GGG CTC TTT CAA GT-3'; reverse: $5^{\prime}$-CGC AAT CAG CCT GAG AGG T-3') were designed using Primer Express (Applied Biosystems), and to prevent potential co-amplification of genomic DNA, the sequence of the UI and CRF forward primer was based on the position of a known exon-exon junction (UI, GenBank accession no. AY651778; CRF, GenBank accession no. AY651777). 


\section{Statistical analysis}

Results are presented as mean \pm s.E.M. Differences among values were assessed by a one-way ANOVA followed by a pairwise Student-Newman-Keuls multiple comparison test. The relationship between CRF and UI mRNA levels within a given region or between the POA and the CNSS for a given transcript were analyzed with the Pearson product moment correlation test. The significance level for all statistical tests was $P<0 \cdot 05$.

\section{Results}

\section{CNS distribution of CRF and UI gene expression}

The quantitative analysis of CRF mRNA levels identified the POA and the CNSS as the primary sites of CRF gene expression in the CNS of rainbow trout, with each region accounting for $\sim 40 \%$ of total expression (Fig. 1B). The CRF gene expression was detected in every region of the CNS, with the olfactory bulbs, optic tectum, midbrain, and hypothalamus accounting for an additional $18 \%$ of total CRF expression, and the telencephelon, cerebellum, hindbrain, and pituitary accounting for the remaining $2 \%$. The UI gene expression was most prominent in the POA, the midbrain, and the CNSS, accounting for $22 \%, 21 \%$, and $18 \%$ of total CNS expression respectively (Fig. 1C). Included in a group of CNS regions with intermediate levels of UI gene expression were the telencephelon (11\%), the hypothalamus (9\%), the olfactory bulbs $(8 \%)$, the hindbrain $(8 \%)$, and the optic tectum $(3 \%)$. Finally, UI gene expression was lowest in the cerebellum and pituitary, which together accounted for less than $1 \%$ of the total expression in the CNS. Direct comparison of the mRNA levels of CRF and UI shows that both transcripts are equally abundant in the POA and the CNSS, and that UI is more abundant than CRF in the olfactory bulbs, telencephalon, midbrain, hypothalamus, and hindbrain (Fig. 1D).

\section{Experiment 1: ammonia stress}

Total water ammonia concentrations remained constant in both the control and ammonia treatments. The desired water ammonia concentration of $600 \mu \mathrm{mol} / 1$ in the ammoniaexposed treatment was achieved with no significant difference between the $24 \mathrm{~h}(618 \cdot 6 \pm 9 \cdot 1 \mu \mathrm{mol} / 1 ; n=6)$ and $96 \mathrm{~h}$ $(599 \cdot 6 \pm 6 \cdot 8 \mu \mathrm{mol} / \mathrm{l} ; n=12)$ exposures. The control fish were kept at average ammonia concentrations of $0 \cdot 9 \pm 0 \cdot 1(n=6)$ and $1 \cdot 3 \pm 0 \cdot 2(n=12) \mu \mathrm{mol} / 1$ during the 24 and 96-h exposures respectively. Water $\mathrm{pH}$ remained constant at $7 \cdot 9$ in all tanks throughout both exposures. After $24 \mathrm{~h}$ of exposure, plasma ammonia was significantly increased in the ammonia-exposed fish $(1343 \cdot 0 \pm 66 \cdot 2 \mu \mathrm{mol} / 1 ; n=12)$ relative to the control fish $(178 \cdot 6 \pm 15 \cdot 7 \mu \mathrm{mol} / 1 ; n=12)$. After $96 \mathrm{~h}$ of exposure, while plasma ammonia in the ammonia-exposed fish (914.8 \pm $26.7 \mu \mathrm{mol} / 1 ; n=12)$ was still higher than in the control fish
$(164 \cdot 2 \pm 16 \cdot 0 \mu \mathrm{mol} / 1 ; n=12)$, there was also a significant recovery in the ammonia-treated fish relative to the 24-h value. Chronic ammonia exposure was also associated with a significant tenfold increase in plasma cortisol after $24 \mathrm{~h}$ and a recovery to control values after $96 \mathrm{~h}$ (Fig. 2A). Similarly, in the POA, ammonia exposure resulted in $2 \cdot 6$ - and $2 \cdot 3$-fold increase in CRF and UI mRNA levels after $24 \mathrm{~h}$ (Fig. 3A and B), respectively, and a return to control values (CRF; Fig. 3A) or a significant decrease (UI; Fig. 3B) after 96 h. In the CNSS, by contrast, the ammonia treatment had no apparent effect after $24 \mathrm{~h}$ of exposure but resulted in 8.7- and 6.7-fold increase in CRF and UI mRNA levels, respectively, after $96 \mathrm{~h}$ of exposure (Fig. 3C and D).

\section{Experiment 2: hypoxia stress}

The desired hypoxic level was achieved within $2 \mathrm{~h}$ and maintained at $\pm 2 \%$ of the target level throughout the experiment. Control fish kept in normoxic water had relatively constant and low plasma cortisol levels, whereas the hypoxic fish
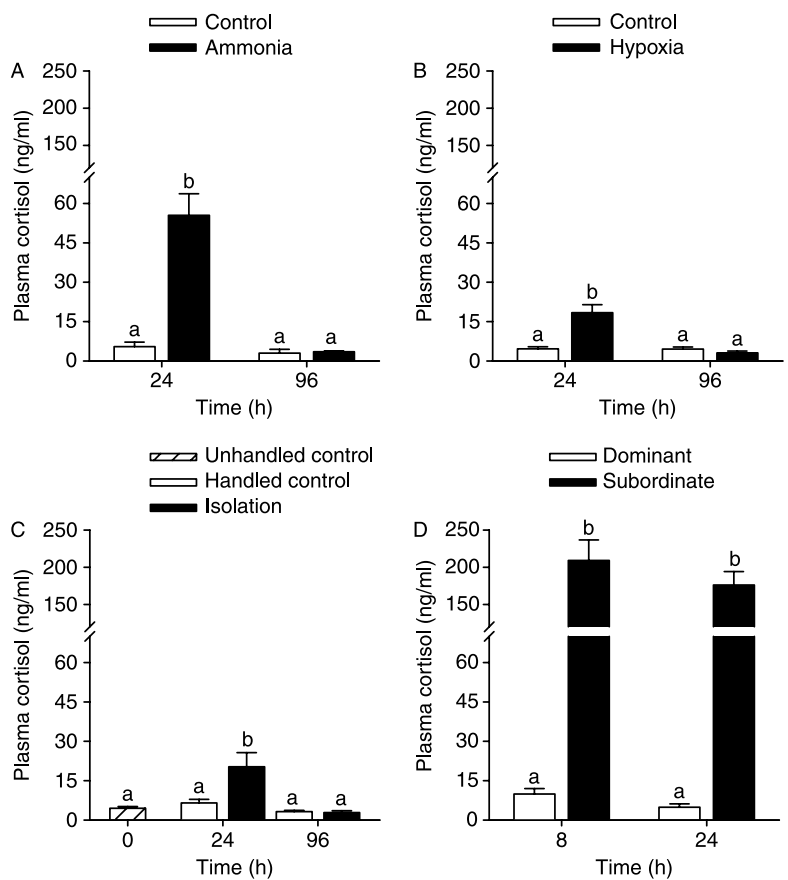

Figure 2 Plasma (cortisol) of rainbow trout (A) exposed to 0 (control) or 600 (ammonia) $\mu \mathrm{mol} / \mathrm{l} \mathrm{NH}_{4} \mathrm{Cl}$ for 24- or 96-h periods $(n=12)$; (B) exposed to $100 \%$ (control) or $35 \%$ (hypoxia) $\mathrm{O}_{2}$ saturation for 24- or 96-h periods $(n=12)$; (C) left undisturbed (unhandled control), anesthetized and returned to their original 125 I tank for either 24 or $96 \mathrm{~h}$ (handled control), or anesthetized and individually confined to 9 I tanks for either 24 or $96 \mathrm{~h}$ (isolation) $(n=11)$; and (D) allowed to interact in size-matched pairs for either 8 or $24 \mathrm{~h}$ and identified as either dominant or subordinate through behavioral observations $(n=8)$. Values are means + S.E.M. For a given stressor, bars that do not share a common letter are significantly different from each other as determined by one-way ANOVA and by pairwise Student-Newman-Keuls test $(P<0 \cdot 05)$. 

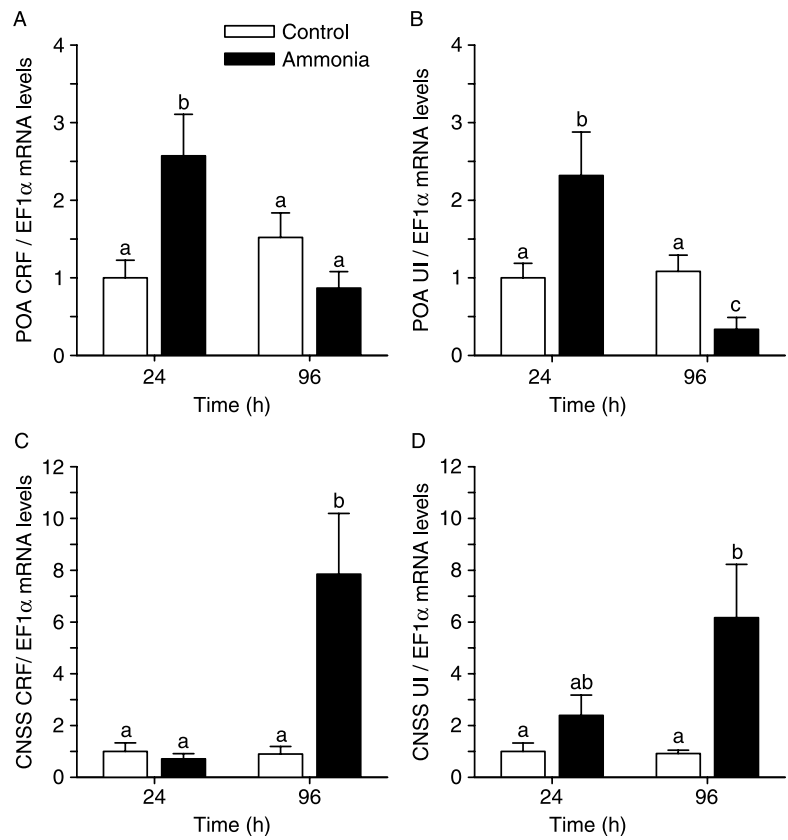

Figure 3 The ratio of corticotropin-releasing factor (CRF; A and C) or urotensin I (UI; B and D) mRNA levels to elongation factor $1 \alpha$ $(\mathrm{EF} 1 \alpha) \mathrm{mRNA}$ levels in the preoptic area (POA; A and B) and caudal neurosecretory system (CNSS; $\mathrm{C}$ and $\mathrm{D}$ ) of rainbow trout exposed to

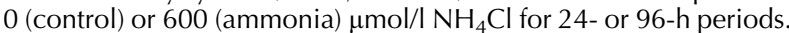
Values are means +S.E.M. $(n=12)$. For comparative purposes, the expression ratios are presented relative to the respective 24-h control value. Bars that do not share a common letter are significantly different from each other as determined by one-way ANOVA and by pairwise Student-Newman-Keuls test $(P<0 \cdot 05)$.

were characterized by a significant fourfold increase in plasma cortisol after $24 \mathrm{~h}$ of exposure and a return to control values after $96 \mathrm{~h}$ (Fig. 2B). Hypoxia also elicited transient changes in POA CRF and UI mRNA levels (Fig. 4A and B). Relative to the control $100 \% \mathrm{O}_{2}$ saturation treatment, exposure to $35 \% \mathrm{O}_{2}$ saturation resulted in $2 \cdot 4$ - and $2 \cdot 1$-fold increase in CRF and UI mRNA levels after $24 \mathrm{~h}$, respectively, and a return to control values after $96 \mathrm{~h}$. While the hypoxic treatment was associated with a similar transient $2 \cdot 7$-fold increase in CRF expression in the CNSS at $24 \mathrm{~h}$, it had no apparent impact on the CNSS UI mRNA levels at either time point (Fig. 4C and D).

\section{Experiment 3: isolation stress}

Relative to both the unhandled and handled control groups, fish exposed to the isolation stressor were characterized by a transient fourfold increase in plasma cortisol concentrations after $24 \mathrm{~h}$ and a return to control levels after $96 \mathrm{~h}$ (Fig. 2C). The isolation conditions also elicited three- to fourfold increase in POA CRF and UI mRNA levels at 24 and $96 \mathrm{~h}$ (Fig. 5A and B). The sustained increase in POA CRF and UI gene expression contrasted with the transient increase in plasma cortisol. In the CNSS, isolation did not affect CRF and UI mRNA levels at $24 \mathrm{~h}$
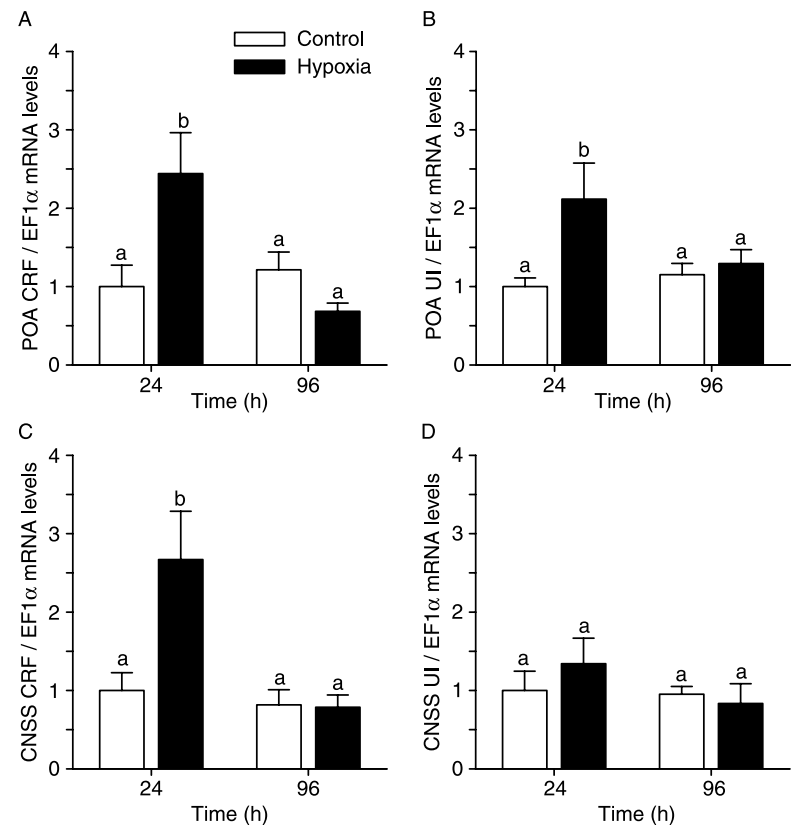

Figure 4 The ratio of corticotropin-releasing factor (CRF; A and C) or urotensin I (UI; B and D) mRNA levels to elongation factor $1 \alpha$ $($ EF1 $\alpha$ ) mRNA levels in the preoptic area (POA; A and B) and caudal neurosecretory system (CNSS; C and D) of rainbow trout exposed to $100 \%$ (control) or $35 \%$ (hypoxia) $\mathrm{O}_{2}$ saturation for 24 - or $96-\mathrm{h}$ periods. Values are means +S.E.M. $(n=12)$. For comparative purposes, the expression ratios are presented relative to the respective 24 -h control value. Bars that do not share a common letter are significantly different from each other as determined by one-way ANOVA and by pairwise Student-Newman-Keuls test $(P<0 \cdot 05)$

but resulted in a significant decrease in the level of both transcripts at $96 \mathrm{~h}$ (Fig. 5C and D).

\section{Experiment 4: subordination stress}

The behavioral observations enabled a clear distinction between the dominant and subordinate animal within all 16 pairs of fish. In general, while dominant fish attacked and chased the fish with subordinate social status, controlled the open space within the water column and monopolized food acquisition, subordinate fish avoided confrontation, remained almost motionless either at the bottom or surface of the aquarium, and acquired little to no food. Instead of the 96-h exposure periods used in Experiments 1-3, social interactions within pairs of fish were monitored over a $24-\mathrm{h}$ period as preliminary experiments revealed that social subordination is a much more acute stressor than either ammonia exposure, hypoxia, or isolation. Relative to the dominant fish, subordination was associated with marked 21- and 36-fold increase in plasma cortisol concentrations after 8 and $24 \mathrm{~h}$ of interaction respectively (Fig. 2D). In contrast, the cortisol concentration of dominant fish reflects that of control fish in Experiments 1-3. In the POA, while subordination stress was characterized by more than twofold increase in CRF 

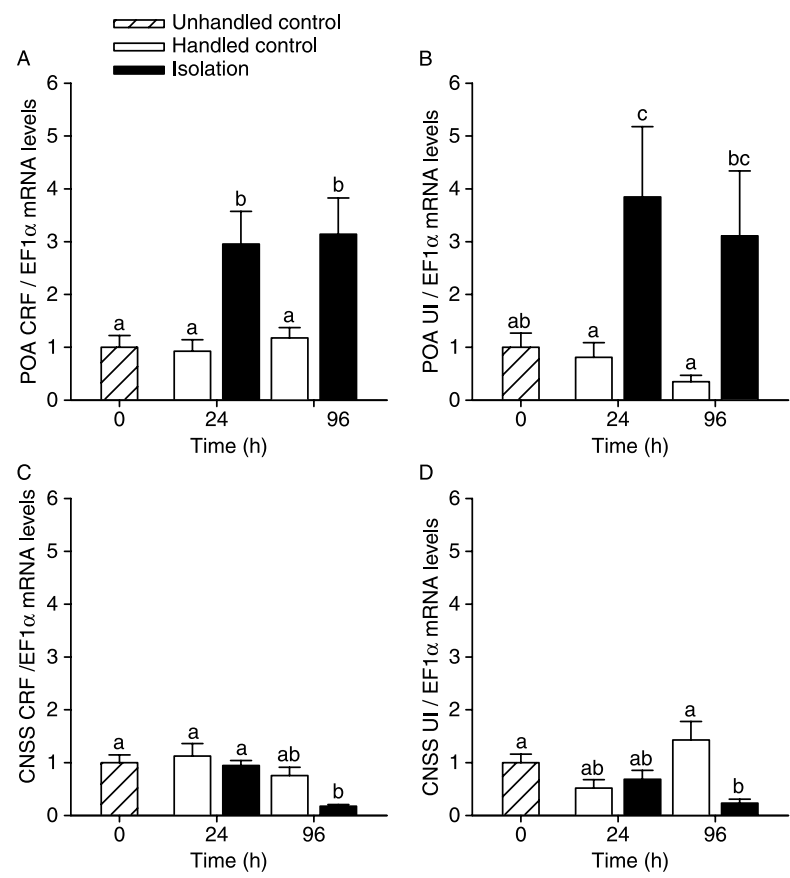

Figure 5 The ratio of corticotropin-releasing factor (CRF; $A$ and $C$ ) or urotensin I (UI; B and D) mRNA levels to elongation factor $1 \alpha$ $($ EF1 $\alpha$ ) mRNA levels in the preoptic area (POA; A and B) and caudal neurosecretory system (CNSS; $\mathrm{C}$ and D) of rainbow trout left undisturbed (unhandled control), anesthetized, and returned to their original $125 \mathrm{I}$ tank for either 24 or $96 \mathrm{~h}$ (handled control), or anesthetized and individually confined to $9 \mathrm{I}$ tanks for either 24 or $96 \mathrm{~h}$ (isolation). Values are means + S.E.M. $(n=11)$. For comparative purposes, the expression ratios are presented relative to the respective 0-h unhandled control value. Bars that do not share a common letter are significantly different from each other as determined by one-way ANOVA and by pairwise Student-Newman-Keuls test $(P<0 \cdot 05)$.

mRNA levels after 8 and 24 h of interaction, it had no impact on UI expression (Fig. 6A and B). Similarly, subordination had no apparent effect on the CNSS mRNA levels of CRF and UI at the 8 - and 24-h sampling times (Fig. 6C and D).

\section{Correlation of $m R N A$ levels}

In Experiments 1-4, there was a significant positive correlation between the mRNA levels of CRF and UI in the POA and in the CNSS (Table 1). In contrast, independent of the experimental conditions, there was no correlation between the CRF mRNA levels of the POA and the CNSS or between the UI mRNA levels of the POA and the CNSS.

\section{Discussion}

This study provides original evidence of stressor-specific CRF and UI transcriptional activity in a teleost species. Overall, among the four stressors tested, no two stressors elicited the same gene expression responses in rainbow trout. While the responses to all stressors after $24 \mathrm{~h}$ of chronic exposure were characterized by increase in plasma cortisol and POA CRF mRNA levels, they differed with regards to the pattern, the timing, and the magnitude of POA UI expression and CNSS CRF and UI mRNA levels.

\section{CNS distribution of CRF and UI gene expression}

The distribution of CRF mRNA levels obtained in this study is consistent with the results of Doyon et al. (2003) and clearly shows that the POA is the primary site of CRF expression in the brain of rainbow trout. Although the presence of CRF in the POA has been reported in many teleost species, the overall expression pattern of CRF in the CNS of rainbow trout appears to differ substantially from the distribution observed in tilapia (Oreochromis mossambicus) where the primary site of CRF immunoreactive cells is in the lateral part of the ventral telencephalon (Pepels et al. 2002). In accordance with the strong in situ hybridization signal previously observed in the CNSS of rainbow trout (Craig et al. 2005), our distribution survey identified the CNSS as an equally important site of CRF gene expression as the POA.
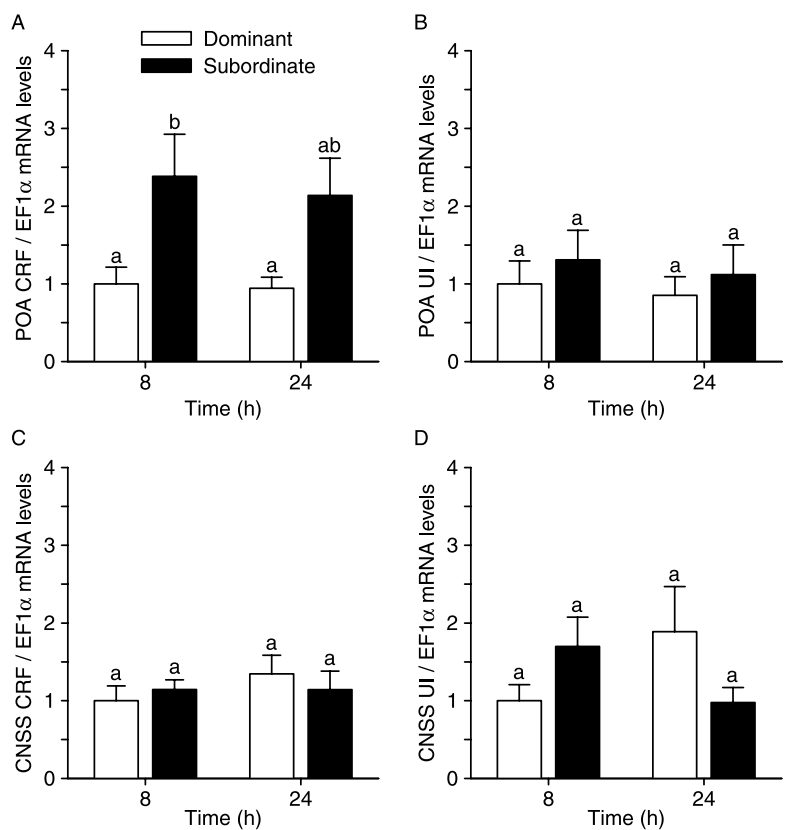

Figure 6 The ratio of corticotropin-releasing factor (CRF; A and C) or urotensin I (UI; B and D) mRNA levels to elongation factor $1 \alpha$ $(\mathrm{EF} 1 \alpha)$ mRNA levels in the preoptic area (POA; A and B) and caudal neurosecretory system (CNSS; C and D) of size-matched rainbow trout allowed to interact for either 8 or $24 \mathrm{~h}$ and identified as either dominant or subordinate through behavioral observations. Values are means + S.E.M. $(n=8)$. For comparative purposes, the expression ratios are presented relative to the respective 8-h dominant value. Bars that do not share a common letter are significantly different from each other as determined by one-way ANOVA and by pairwise Student-Newman-Keuls test $(P<0 \cdot 05)$. 
Table 1 Correlation between corticotropin-releasing factor (CRF) and urotensin I (UI) mRNA levels within a given tissue or between the preoptic area (POA) and the caudal neurosecretory system (CNSS) for a given transcript in rainbow trout exposed to four different stressors: hyperammonemia, hypoxia, isolation, and subordination

\begin{tabular}{|c|c|c|c|c|c|}
\hline & mRNA levels of variable 1 & mRNA levels of variable 2 & $R^{2}$ value $^{\mathrm{a}}$ & $P$ value & $n$ value \\
\hline \multirow[t]{3}{*}{ Experiment 1: hyperammonemia } & POA-CRF & POA-UI & $0 \cdot 427$ & $<0 \cdot 001$ & 48 \\
\hline & POA-CRF & CNSS-CRF & $0 \cdot 019$ & $0 \cdot 483$ & 48 \\
\hline & POA-UI & CNSS-UI & $0 \cdot 029$ & $0 \cdot 390$ & 48 \\
\hline \multirow[t]{2}{*}{ Experiment 2: hypoxia } & POA-CRF & POA-UI & $0 \cdot 333$ & $<0 \cdot 001$ & 48 \\
\hline & CNSS-CRF & CNSS-UI & $0 \cdot 490$ & $<0 \cdot 001$ & 48 \\
\hline \multirow[t]{4}{*}{ Experiment 3: isolation } & POA-CRF & POA-UI & $0 \cdot 544$ & $<0 \cdot 001$ & 55 \\
\hline & CNSS-CRF & CNSS-UI & $0 \cdot 883$ & $<0 \cdot 001$ & 55 \\
\hline & POA-CRF & CNSS-CRF & $0 \cdot 008$ & $0 \cdot 622$ & 55 \\
\hline & POA-UI & CNSS-UI & $0 \cdot 055$ & $0 \cdot 197$ & 55 \\
\hline \multirow[t]{2}{*}{ Experiment 4: subordination } & POA-CRF & POA-UI & $0 \cdot 692$ & $<0 \cdot 001$ & 32 \\
\hline & CNSS-CRF & CNSS-UI & $0 \cdot 505$ & $<0 \cdot 001$ & 32 \\
\hline
\end{tabular}

${ }^{a}$ The relationships between the mRNA levels were analyzed with the Pearson product moment correlation test. All values within a given experiment, including those from all control and treatment groups, were used to calculate the coefficient of determination $\left(R^{2}\right)$ for a given relationship.

To what extent the CNS pattern of CRF gene expression observed in rainbow trout is characteristic of other teleosts is not known. To date, in the only other teleost species where CRF expression has been localized to the CNSS, the flounder (Lu et al. 2004), a quantitative distribution pattern has not been performed.

Overall, the distribution of UI gene expression in the CNS of rainbow trout is more widespread than that of CRF. Similar to the expression pattern of CRF as described above, the POA and the CNSS are among the principal sites of UI expression in the CNS. While several studies have previously identified the CNSS as a major site of UI expression in teleosts (Winter et al. 2000, Lu et al. 2004, Craig et al. 2005), the POA was only recently recognized in zebrafish as a site of CRF and UI co-expression (Alderman \& Bernier 2007). We also identified the midbrain as a primary site of UI gene expression in the CNS of rainbow trout. In zebrafish, three midbrain nuclei show a strong UI hybridization signal, the nucleus of the medial longitudinal fascicle, the dorsal tegmental nucleus, and the nucleus lateralis valvulae (Alderman \& Bernier 2007). While the present study focused on the POA and the CNSS, our results also point to the need for future studies to identify the functional role of the UI-expressing cells of the midbrain in the stress response of fish.

\section{Effects of stressors on plasma cortisol}

Consistent with their designation as stressors and with previous studies on rainbow trout where these treatments were applied (Overli et al. 1999, Sloman et al. 2001, Wicks \& Randall 2002, Doyon et al. 2003, 2005, Bernier \& Craig 2005, Ortega et al.
2005), all four challenges elicited an increase in plasma cortisol. Comparison of the magnitude of the cortisol responses $24 \mathrm{~h}$ into the different treatments shows that subordination was the most severe stressor in this study, followed by ammonia exposure, and finally by the isolation and hypoxia stressors. In contrast, the plasma cortisol levels in the control treatments of the ammonia and hypoxic challenges, in both the unhandled and handled control groups of the isolation stress, and in the dominant fish of Experiment 4 were all characteristic of unstressed rainbow trout (Barton \& Iwama 1991).

Despite the chronic nature of the treatments, the cortisol response in the ammonia, hypoxia, and isolation stressors were transient. The return of plasma cortisol levels to basal conditions and the partial recovery in plasma ammonia in rainbow trout chronically exposed to elevated ammonia levels for $96 \mathrm{~h}$ are consistent with the results of previous studies (Wicks \& Randall 2002, Ortega et al. 2005), and likely result from the ammonia detoxifying mechanisms recruited upon continued exposure to this environmental stressor (Randall \& Tsui 2002). Similarly, the physiological and behavioral responses associated with chronic hypoxia in rainbow trout (Randall 1982, Boutilier et al. 1988, Bernier \& Craig 2005) may serve to reduce the threat to homeostasis and dampen the HPI axis response. The transient increase in plasma cortisol in the chronically isolated and confined fish corroborates the results of Doyon et al. (2005) and suggests that habituation to this social stressor is taking place at the level of the HPI axis. In contrast, while we did not assess the long-term effects of fights for social dominance on plasma cortisol levels, several previous studies have shown that subordination is a chronic stressor in rainbow trout and that plasma cortisol levels remain elevated 
for up to 2 weeks (Laidley \& Leatherland 1988, Winberg \& Lepage 1998, Sloman et al. 2001). Assessed in pairs, the subordinate fish cannot avoid the dominant fish and is therefore subjected to constant stress.

\section{Contribution of CRF and UI to the regulation of plasma cortisol}

In keeping with the proposed function of POA CRF as a key player in the regulation of the HPI axis and the endocrine stress response in fish (Flik et al. 2006), all four stressors elicited an increase in POA CRF mRNA expression. Interestingly, however, the magnitude and duration of the increase in POA CRF expression did not correlate with the magnitude and duration of the stress-induced HPI axis response. For example, while the subordinate fish in Experiment 4 were characterized by plasma cortisol levels that were four to ten times higher than those of any other fish in this study, the increase in POA CRF mRNA levels of these fish was equal to or smaller than the increase observed in response to the three other stressors. Furthermore, while POA UI gene expression did increase in response to some of the environmental and social challenges tested, we did not detect any changes in POA UI mRNA expression in response to subordination.

Several factors may have contributed to the apparent disconnect noted above between the expression pattern of the CRF-related peptides in the POA and the activity of the HPI axis in rainbow trout. If CRF and UI are both capable of influencing HPI axis activity, their combined hypophysiotropic actions may mask any correlation between the expression pattern of either transcript and plasma cortisol. In addition to the possibility that changes in gene expression may not accurately predict or reflect peptide secretion, the lack of correlation between POA CRF-related peptide mRNA levels and plasma cortisol concentrations may also be due to changes in other components of the CRF system not addressed in this study. For example, changes in the pituitary concentration of CRF-binding protein or corticotrope CRF receptors could modify the impact of CRFrelated peptides on the activity of the HPI axis (Huising et al. 2004). Alternatively, the discrepancy could be a product of the functional organization of the POA. In mammals, the PVN comprised several CRF-expressing cell types that are differentially recruited according to the stressor and that govern different neuroendocrine, autonomic, and behavioral mechanisms (Sawchenko et al. 2000). Assuming the CRFrelated peptide-expressing neurons of the POA in fish are organized in a similar fashion as those of the mammalian PVN, then the POA CRF and UI gene expression data reported in this study may reflect not only the contribution of the CRF-related peptides to the regulation of neuroendocrine functions but also their potential contributions to the regulation of autonomic and behavioral pathways. In zebrafish, CRF and UI are expressed in several different cellular divisions of the POA (Alderman \& Bernier 2007). Therefore, future studies in fish are needed to determine whether the different CRF-related peptide-expressing cell types of the POA govern different functions and whether these are differentially regulated.

In addition to POA CRF and UI there is evidence that the CRF-related peptides of the CNSS may also contribute to the regulation of cortisol secretion. For example, in rainbow trout, UI can directly stimulate interrenal cortisol secretion and potentiate the steroidogenic actions of $\mathrm{ACTH}$ in vitro (Arnold-Reed \& Balment 1994). In the same species, the changes in plasma cortisol elicited by a hyperosmotic challenge are accompanied by marked increase in CNSS CRF and UI mRNA expression (Craig et al. 2005). In general, however, our results lend little support for a contribution of CNSS CRF-related peptides to the regulation of cortisol secretion. Among the four stressors assessed none showed coordinated changes in plasma cortisol and CNSS UI mRNA levels, and only one stressor, hypoxia, was characterized by simultaneous increase in plasma cortisol and CNSS CRF expression.

Contrasting effects of stressors on the expression of CRF and UI in the $P O A$

The strong positive correlation between CRF and UI gene expression in the POA of fish exposed to hyperammonemia or hypoxia supports our previous findings (Bernier \& Craig 2005, Ortega et al. 2005) and suggests that in response to some challenges the CRF- and UI-expressing neurons of the POA maybe recruited in a similar fashion. Interestingly, isolation, a stressor with significantly different attributes than either hypoxia or hyperammonemia, was also characterized by parallel increase in POA CRF and UI mRNA levels. In this case, however, as previously observed by Doyon et al. (2005) for CRF, the isolation-induced increase in CRF and UI expression were sustained for the duration of the stressor. So while isolation may not pose a chronic threat to homeostasis and HPI axis activity habituation maybe relatively rapid, excitatory pathways involved in relaying the perceived psychological threat of the new environment maybe involved in keeping the CRF and UI mRNA levels elevated through at least $96 \mathrm{~h}$. Similarly, isolation is known to result in a chronic reduction in food intake in rainbow trout (Overli et al. 2002), a behavioral response that maybe at least partially mediated by the CRF-related peptides (Bernier 2006). Lastly, despite eliciting the most pronounced cortisol response among the challenges tested, subordination was only associated with an increase in CRF expression and not UI. Therefore, our results and those of Doyon et al. (2003, 2005) suggest that the recruitment of POA CRF neurons is a nearly ubiquitous feature of the stress response in rainbow trout, as previously observed in the PVN of rats (Sawchenko et al. 2000, Dayas et al. 2001). In contrast, although the response may have been missed due to the limitations of our sampling regime, the recruitment of POA UI neurons appears to be stressor-specific and independent of the stress-induced cortisol response. 
Contrasting effects of stressors on the expression of CRF and UI in the CNSS

Prior to this study, only two stressors had been investigated for their impact on the expression of CRF and UI in the CNSS, physical restraint (Lu et al. 2004) and seawater transfer (Craig et al. 2005). Whereas physical restraint in flounder was associated with a transient increase in CRF expression and no changes in UI mRNA levels (Lu et al. 2004), seawater transfer in rainbow trout elicited chronic parallel increase in CRF and UI mRNA levels (Craig et al. 2005). Here we show that two additional environmental stressors, hyperammonemia and hypoxia, stimulate the expression of CRF-related peptides in the CNSS. In contrast, isolation induced a delayed decrease in the expression of CRF and UI, and subordination stress had no impact. Taken together, these results indicate that the CRF- and UI-expressing neurons of the CNSS can be recruited differentially and only in response to specific stimuli.

Although the specific identity of the neural inputs that provide for stressor-specific recruitment of the CRF- and UI-expressing cells of the CNSS are not known, there is clear morphological evidence that descending pathways from the brain reach the Dahlgren cells (Kriebel et al. 1985, Kobayashi et al. 1986). Indeed, the results from electrophysiological and pharmacological studies suggest that the Dahlgren cells are subject to a complex balance of excitatory and inhibitory input of both extrinsic and intrinsic origin (see McCrohan et al. 2007 for review). To date, however, only one type of stressor, osmotic disturbances, has been shown to activate descending pathways that modulate Dahlgren cell activity (Ashworth et al. 2005). While hyperammonemia and hypoxia may elicit small ionic disturbances (Thomas et al. 1986, Knoph \& Thorud 1996), the changes in CNSS CRF and UI expression in response to these stressors differ markedly from those elicited by seawater transfer (Craig et al. 2005). Therefore, the increase in CNSS CRF-related peptide mRNA levels in response to hyperammonemia and hypoxia are unlikely to result from the stimulation of osmoreceptorsensitive regulatory pathways. Instead, since electrical stimulation of branchial nerve branches can affect Dahlgren cell activity (Ashworth et al. 2005), we raise the possibility that the afferent fibers from the gill chemoreceptors involved in mediating hypoxic reflexes also synapse onto descending pathways that reach the CNSS. In contrast, if ammonia neurotoxicity in fish results from a local synaptic excess of glutamate as proposed by Walsh et al. (2007), then the stimulatory effects of hyperammonemia on the CRF- and UI-expressing cells of the CNSS are more likely to be of local rather than extrinsic origin.

\section{Correlation of CRF and UI $m R N A$ levels within and between regions}

A novel finding from this study is the high degree of correlation, independent of the stressor, between the mRNA levels of CRF and UI within the POA and the CNSS.
Interestingly, the positive correlations between CRF and UI expression within a region were observed even when only one of the two transcripts significantly increased in response to a given stressor. These results suggest that the regulation of CRF and UI gene expression within the POA or the CNSS are not independent from one another. In the CNSS, the partial co-regulation of CRF-related peptide expression maybe explained by the high degree of CRF and UI co-localization. In the flounder, more than $90 \%$ of the Dahlgren cells are immunoreactive for both CRF and UI, and in some axon terminals of the urophysis these peptides are co-localized to the same neurosecretory granules $(\mathrm{Lu}$ et al. 2004, McCrohan et al. 2007). Similarly, in situ hybridization revealed an overlapping pattern of CRF and UI expression throughout the CNSS of rainbow trout (Craig et al. 2005). In the POA, while co-expression of CRF and UI has not been ascertained, the expression pattern of these peptides appears to overlap in the parvocellular nucleus of the zebrafish POA (Alderman \& Bernier 2007). Overall, as previously suggested (Alderman \& Bernier 2007, McCrohan et al. 2007), our results indicate that CRF and $\mathrm{UI}$ in the POA and the CNSS may have shared roles and exhibit partial functional redundancy.

By contrast, we did not find any correlation in the mRNA levels of either CRF or UI between the POA and the CNSS. So, while morphological studies have suggested that distinct neuronal cell groups of the medulla maybe involved in coordinating the response from the cranial and caudal neuro secretory systems (Kriebel et al. 1985), our results indicate that the CRF- and UI-expressing neurons of the POA and the CNSS in rainbow trout maybe differentially regulated and in general do not respond to stressors along a common time frame. Although the CRF-related peptides of the POA and CNSS may share some physiological roles, e.g. osmoregulation, the differences in the CRF-related peptide gene expression patterns between the POA and the CNSS noted here suggest marked differences in the overall contribution of these two neurosecretory systems to the maintenance of homeostasis.

\section{Conclusions}

In summary, this study demonstrates that the contributions of CRF and UI neurons to the stress response in rainbow trout are stressor-, time-, and region-specific. While the diverse challenges tested in this study all stimulated CRF expression in the POA, the recruitment of POA UI and CNSS CRF and UI neurons was stressor-specific and independent of plasma cortisol levels. Therefore, while our results provide support for the proposed role of POA CRF as a key player of the endocrine stress response in fish, they also suggest that POA UI and the CRF-related peptides of the CNSS support additional features of the multifaceted response to stressors. Since all the CRF or UI neurons of the POA are unlikely to function as a singular entity, part of the challenge ahead is to 
determine whether the distinct groupings of the CRF- and UI-expressing cells within the POA differentially respond to stressors on the basis of their attributes and their duration. Similarly, studies are needed to map the degree of connectivity between the POA and the CNSS, and to assess the cellular mechanisms responsible for the differential response of the CNSS to stressors.

\section{Acknowledgements}

The authors would like to thank Bob Frank and Matt Cornish for their technical assistance in the Hagen Aqualab. This research was supported by an Ontario Graduate Scholarship to S L A and by a Natural Sciences and Engineering Research Council of Canada Discovery grant to N J B. The authors declare that there is no conflict of interest that would prejudice the impartiality of this scientific work.

\section{References}

Alderman SL \& Bernier NJ 2007 Localization of corticotropin-releasing factor, urotensin I, and CRF-binding protein gene expression in the brain of the zebrafish, Danio rerio. Journal of Comparative Neurology 502 783-793.

Arnold-Reed DE \& Balment RJ 1994 Peptide hormones influence in vitro interrenal secretion of cortisol in the trout, Oncorhynchus mykiss. General and Comparative Endocrinology 96 85-91.

Ashworth AJ, Banks JR, Brierley MJ, Balment RJ \& McCrohan CR 2005 Electrical activity of caudal neurosecretory neurons in seawater and freshwater-adapted Platichthys flesus, in vivo. Journal of Experimental Biology 208 267-275.

Bakshi VP \& Kalin NH 2000 Corticotropin-releasing hormone and animal models of anxiety: gene-environment interactions. Biological Psychiatry 48 1175-1198.

Barton BA \& Iwama GK 1991 Physiological changes in fish from stress in aquaculture with emphasis on the response and effects of corticosteroids. Annual Review of Fish Diseases $13-26$.

Bernier NJ 2006 The corticotropin-releasing factor system as a mediator of the appetite-suppressing effects of stress in fish. General and Comparative Endocrinology 146 45-55.

Bernier NJ \& Craig PM 2005 CRF-related peptides contribute to stress response and regulation of appetite in hypoxic rainbow trout. American Journal of Physiology. Regulatory, Integrative and Comparative Physiology 289 R982-R990.

Boorse GC, Crespi EJ, Dautzenberg FM \& Denver RJ 2005 Urocortins of the South African clawed frog, Xenopus laevis: conservation of structure and function in tetrapod evolution. Endocrinology 11 4851-4860.

Boutilier RG, Dobson G, Hoeger U \& Randall DJ 1988 Acute exposure to graded levels of hypoxia in rainbow trout (Salmo gairdneri): metabolic and respiratory adaptations. Respiration Physiology 71 69-82.

Chang CL \& Hsu SYT 2004 Ancient evolution of stress-regulating peptides in vertebrates. Respiration Physiology 25 1681-1688.

Craig PM, Al-Timimi H \& Bernier NJ 2005 Differential increase in forebrain and caudal neurosecretory system corticotropin-releasing factor and urotensin I gene expression associated with seawater transfer in rainbow trout. Endocrinology 146 3851-3860.

Dayas CV, Buller KM, Crane JW, Xu Y \& Day TA 2001 Stressor categorization: acute physical and psychological stressors elicit distinctive recruitment patterns in the amygdala and in medullary noradrenergic cell groups. European Journal of Neuroscience 14 1143-1152.
Doyon C, Gilmour KM, Trudeau VL \& Moon TW 2003 Corticotropinreleasing factor and neuropeptide $\mathrm{Y}$ mRNA levels are elevated in the preoptic area of socially subordinate rainbow trout. General and Comparative Endocrinology 133 260-271.

Doyon C, Trudeau VL \& Moon TW 2005 Stress elevates corticotropinreleasing factor (CRF) and CRF-binding protein mRNA levels in rainbow trout (Oncorhynchus mykiss). Journal of Endocrinology 186 123-130.

Flik G, Klaren PHM, Van den Burg EH, Metz JR \& Huising MO 2006 CRF and stress in fish. General and Comparative Endocrinology 146 36-44.

Fryer J, Lederis K \& Rivier J 1983 Urotensin I, a CRF-like neuropeptide, stimulates ACTH release from the teleost pituitary. Endocrinology 113 2308-2310.

Huising MO, Metz JR, van Schooten C, Taverne-Thiele AJ, Hermsen T, Verberg-van Kemenade BML \& Flik G 2004 Structural characterization of a cyprinid (Cyprinus carpio L.) CRH, CRH-BP and CRH-R1, and the role of these proteins in the acute stress response. Journal of Molecular Endocrinology 32 627-648.

Kelsall CJ \& Balment RJ 1998 Native urotensins influence cortisol secretion and plasma cortisol concentration in the euryhaline flounder, Platichthys flesus. General and Comparative Endocrinology 112 210-219.

Knoph MB \& Thorud K 1996 Toxicity of ammonia to Atlantic salmon (Salmo salar L.) in seawater - effects on plasma osmolality, ion, ammonia, urea and glucose levels and hematologic parameters. Comparative Biochemistry and Physiology 113A 375-381.

Kobayashi H, Owada K, Yamada C \& Okawara Y 1986 The caudal neurosecretory system in fishes. In Vertebrate Endocrinology: Fundamentals and Biomedical Implications, vol 1, Morphological Considerations pp 147-174. Eds PKT Pang, MP Schreibman \& A Gorbman. Orlando: Academic Press.

Kriebel RM, Parsons RL \& Miller KE 1985 Innervation of caudal neurosecretory cells. In Neurosecretion and the Biology of Neuropeptides, pp 457-463. Eds H Kobayashi, H Bern \& A Urano. Tokyo: Japan Scientific Societies Press.

Kun E \& Kearney EB 1971 Ammonia, Methods of Enzymatic Analysis vol 4, pp 1802-1806. Ed. HU Bergmeyer. New York: Academic Press.

Laidley CW \& Leatherland JF 1988 Cohort sampling, anaesthesia and stocking-density effects on plasma cortisol, thyroid hormone, metabolite and ion levels in rainbow trout, Salmo gairdneri Richardson. Journal of Fish Biology 33 73-88.

Larsen DA, Swanson P, Dickey JT, Rivier J \& Dickhoff WW 1998 In vitro thyrotropin-releasing activity of corticotropin-releasing hormone-family peptides in coho salmon, Oncorhynchus kisutch. General and Comparative Endocrinology 109 276-285.

Lovejoy DA \& Balment RJ 1999 Evolution and physiology of the corticotropin-releasing factor (CRF) family of neuropeptides in vertebrates. General and Comparative Endocrinology 115 1-22.

Lowry CA \& Moore FL 2006 Regulation of behavioral responses by corticotropin-releasing factor. General and Comparative Endocrinology 14619-27.

Lu W, Dow L, Gumusgoz S, Brierly MJ, Warne JM, McCrohan CR, Balment RJ \& Riccardi D 2004 Coexpression of corticotropin-releasing hormone and urotensin I precursor genes in the caudal neurosecretory system of the euryhaline flounder (Platichthys flesus): a possible shared role in peripheral regulation. Endocrinology 145 5786-5797.

Lu W, Worthington J, Riccardi D, Balment RJ \& McCrohan CR 2007 Seasonal changes in peptide, receptor and ion channel mRNA expression in the caudal neurosecretory system of the European flounder (Platichthys flesus). General and Comparative Endocrinology 153 262-272.

Matz SP \& Hofeldt GT 1999 Immunohistochemical localization of corticotropin-releasing factor in the brain and corticotropin-releasing factor and thyrotropin-stimulating hormone in the pituitary of chinook salmon (Oncorhynchus tshawytscha). General and Comparative Endocrinology 114 151-160

McCrohan C \& Bernier N 2007 New insights into urotensin endocrinology: from fish to man. General and Comparative Endocrinology 153 241-242.

McCrohan CR, Lu W, Brierley MJ, Dow L \& Balment RJ 2007 Fish caudal neurosecretory system: a model for the study of neuroendocrine secretion. General and Comparative Endocrinology 153 243-250. 
Le Mével J-C, Mimassi N, Lancien F, Mabin D \& Conlon JM 2006 Cardiovascular actions of the stress-related neurohormonal peptides, corticotropin-releasing factor and urotensin-I in the trout Oncorhynchus mykiss. General and Comparative Endocrinology 146 56-61.

Ortega VA, Renner KJ \& Bernier NJ 2005 Appetite-suppressing effects of ammonia exposure in rainbow trout associated with regional and temporal activation of brain monoaminergic and CRF systems. Journal of Experimental Biology 208 1855-1866.

Overli O, Harris CA \& Winberg S 1999 Short-term effects of fights for social dominance and the establishment of dominant-subordinate relationships on brain monoamines and cortisol in rainbow trout. Brain, Behavior and Evolution 54 263-275.

Overli O, Pottinger TG, Carrick TR, Overli E \& Winberg S 2002 Differences in behaviour between rainbow trout selected for high- and low-stress responsiveness. Journal of Experimental Biology 205 391-395.

Pepels PPLM, Meek J, Wendelaar Bonga SE \& Balm PHM 2002 Distribution and quantification of corticotropin-releasing hormone (CRH) in the brain of the teleost fish Oreochromis mossambicus (Tilapia). Journal of Comparative Neurology 453 247-268.

Pepels PPLM, van Helvoort H, Wendelaar Bonga SE \& Balm PHM 2004 Corticotropin-releasing hormone in the teleost stress response: rapid appearance of the peptide in plasma of tilapia (Oreochromis mossambicus). Journal of Endocrinology 180 425-438.

Randall DJ 1982 The control of respiration and circulation in fish during exercise and hypoxia. Journal of Experimental Biology 100 275-288.

Randall DJ \& Tsui TKN 2002 Ammonia toxicity in fish. Marine Pollution Bulletin 45 17-23.

Sawchenko PE, Li HY \& Ericsson A 2000 Circuits and mechanisms governing hypothalamic responses to stress: a tale of two paradigms. Progress in Brain Research 122 61-78.

Sloman KA, Metcalfe NB, Taylor AC \& Gilmour KM 2001 Plasma cortisol concentrations before and after social stress in rainbow trout and brown trout. Physiological and Biochemical Zoology 74 383-389.

Swanson LW \& Sawchenko PE 1983 Hypothalamic integration: organization of the paraventricular and supraoptic nuclei. Annual Review of Neuroscience 6 269-324.
Thomas S, Fievet B \& Motais R 1986 Effect of deep hypoxia on acid-base balance in trout: role of ion transfer processes. American Journal of Physiology. Regulatory, Integrative and Comparative Physiology 250 R319-R327.

Tran TN, Fryer JN, Lederis K \& Vaudry H 1990 CRF, urotensin I, and sauvagine stimulate the release of POMC-derived peptides from goldfish neurointermediate lobe cells. General and Comparative Endocrinology 78 351-360.

Verdouw H, Van Echted CJA \& Dekkers EMJ 1978 Ammonia determination based on indophenol formation with sodium salicylate. Water Research 12 399-402.

Walsh PJ, Veauvy CM, McDonald MD, Pamenter ME, Buck LT \& Wilkie MP 2007 Piscine insights into comparisons of anoxia tolerance, ammonia toxicity, stroke and hepatic encephalopathy. Comparative Biochemistry and Physiology 147A 332-343.

Wicks BJ \& Randall DJ 2002 The effect of sub-lethal ammonia exposure on fed and unfed rainbow trout: the role of glutamine in regulation of ammonia. Comparative Biochemistry and Physiology 132A 275-285.

Winberg S \& Lepage O 1998 Elevation of brain 5-HT activity, POMC expression, and plasma cortisol in socially subordinate rainbow trout. American Journal of Physiology. Regulatory, Integrative and Comparative Physiology 274 R645-R654.

Winter MJ, Ashworth A, Bond H, Brierley MJ, McCrohan CR \& Balment RJ 2000 The caudal neurosecretory system: control and function of a novel neuroendocrine system in fish. Biochemistry and Cell Biology 78 193-203.

Zupanc GKH, Horschke I \& Lovejoy DA 1999 Corticotropin-releasing factor in the brain of the gymnotiform fish, Apteronotus leptorhynchus: immunohistochemical studies combined with neuronal tract tracing. General and Comparative Endocrinology 114 349-364.

Received in final form 5 December 2007

Accepted 10 December 2007

Made available online as an Accepted Preprint

10 December 2007 